\title{
The effect of physical aging on the embrittlement of steam-sterilized polycarbonate
}

\author{
Dirk J. A. Senden • Tom A. P. Engels • \\ Serge H. M. Söntjens • Leon E. Govaert
}

Received: 24 February 2012/Accepted: 18 April 2012/Published online: 5 May 2012

(C) The Author(s) 2012. This article is published with open access at Springerlink.com

\begin{abstract}
Polycarbonate is known to suffer from dramatic reductions in ductility upon exposure to hot, humid environments, such as during steam sterilization. Two phenomena have been proposed to be the main causes of this embrittlement: hydrolysis and microcavity formation. The present study focuses on a third phenomenon, whose contribution to the embrittlement has until now been considered insignificant: (physical) aging. By studying the influence of steam sterilization on the tensile deformation behavior of polycarbonate, it is shown that aging actually is one of the dominant factors in the embrittlement.
\end{abstract}

\section{Introduction}

Polycarbonate (PC) is the foremost example of a ductile polymer, and, as such, the material of choice for many engineering applications that require superior impact resistance. However, if exposed to hot environments, PC is known to quickly lose its ductility $[1,2]$. This phenomenon especially limits the use of PC in medical appliances that

D. J. A. Senden - T. A. P. Engels · L. E. Govaert ( ()

Polymer Technology, Mechanical Engineering,

Eindhoven University of Technology (TUE), P.O. Box 513,

5600 MB Eindhoven, The Netherlands

e-mail: 1.e.govaert@tue.nl

T. A. P. Engels

DSM Ahead, Materials Sciences R\&D, P.O. Box 18, 6160 MD Geleen, The Netherlands

S. H. M. Söntjens

SyMO-Chem B.V, Den Dolech 2, 5612 AZ Eindhoven,

The Netherlands are required to withstand steam sterilization, where the combination of high temperature and humidity proves extra demanding. It has been proposed that there are two principal causes for this embrittlement [3]: hydrolysis and microcavity formation.

The molecular weight reduction resulting from the hydrolysis of carbonate groups [3-7] leads to decrease of the tensile strength [8-10] that eventually induces a ductile to brittle transition [11]. At the same time, the ductility of steam-sterilized PC is reduced by the formation of small, disk-shaped microcavities or microcracks [3, 6, 7, 12-15]. Upon exposure to a hot and humid environment, the material becomes saturated with water; subsequent cooling causes supersaturation [7], triggering the formation of water-filled cavities $[3,6,7,12-15]$. The sharp edges of these microcavities act as crack initiation sites, thus promoting brittle fracture $[3,7,14,15]$.

On the other hand, a strong loss of ductility is also observed upon annealing in dry air at high temperature (below the glass transition) $[1,2,16]$. It finds its origin in the increase of the yield stress as a result of (physical) aging ('annealing') [17-20]. This increase in yield stress is accompanied with an increase in intrinsic strain softening, which induces a more severe strain localization [16], promoting an increased build-up of hydrostatic stress that triggers void formation and crazing [2, 21, 22]. This effect is especially prominent in notched samples [2].

Although some researchers have hypothesized an influence of aging on the embrittlement of PC upon steam sterilization [3-5], it has never been thoroughly studied, as it was considered to be subordinate to the effects of hydrolysis and microcavity formation $[4,5]$. In the present study we will demonstrate that, in fact, aging is one of the dominant factors in the embrittlement of steam-sterilized PC. 


\section{Materials and methods}

Three different molecular weight grades of polycarbonate (PC) were used in this study: Lexan OQ1020, Lexan 141R and Lexan 101R (Sabic Innovative Plastics, Bergen op Zoom, the Netherlands). For ease of notation, these grades will be referred to as LM-PC, MM-PC, and HM-PC, respectively. Initial "apparent" molecular weights are listed in Table 1 ( 0 cycles).

Dog-bone shaped tensile bars (ASTM D638) were injection molded and subsequently subjected to steam sterilization using a Boxer Laboratory Equipment LTD 200/50 L autoclave machine, operating at a chamber temperature of $123{ }^{\circ} \mathrm{C}$, a load temperature of $121{ }^{\circ} \mathrm{C}$, a run time of $30 \mathrm{~min}$, and a steam time of $3 \mathrm{~min}$. After each steam-sterilization cycle, the samples were left to cool to room temperature before the next cycle.

Uniaxial tensile tests were performed on a MTS Elastomer Testing System 831 at a strain rate of $10^{-3} \mathrm{~s}^{-1}$ and a temperature of $23^{\circ} \mathrm{C}$. Size exclusion chromatography (SEC) was performed on a Shimadzu LC-10ADVP system with a Shimadzu RID-10A refractive index detector, a Shimadzu SPD-M10AVP UV-Vis detector at $254 \mathrm{~nm}$, and

Table 1 "Apparent" weight-averaged and number-averaged molecular weights of the three polycarbonate grades after 0,7 , and 14 autoclave treatments

\begin{tabular}{lllll}
\hline & Cycles & 0 & 7 & 14 \\
\hline HM-PC & $\bar{M}_{w}$ & 50339 & 50103 & 49582 \\
& $\bar{M}_{n}$ & 19157 & 20076 & 19868 \\
MM-PC & $\bar{M}_{w}$ & 43399 & 41948 & 40577 \\
& $\bar{M}_{n}$ & 19626 & 18863 & 18580 \\
LM-PC & $\bar{M}_{w}$ & 28058 & 27621 & \\
& $\bar{M}_{n}$ & 13620 & 13254 & \\
\hline
\end{tabular}

a serial configuration of a PLgel 5- $\mu$ m mixed-C column and a PLgel 5- $\mu \mathrm{m}$ mixed-D column, using THF as eluent. The recorded molecular weights are reported relative to polystyrene standards and are therefore referred to as "apparent" molecular weights.

\section{Results and discussion}

In the tensile tests, a clear distinction can be made between specimens that display ductile failure, involving considerable macroscopic plastic deformation, and specimens that show brittle failure. Figure 1a shows tensile curves for HM-PC after 0, 5, 10, and 15 steam-sterilization cycles; the reduction in ductility is clearly visible. Figure $1 \mathrm{~b}$ depicts the failure stress for all three PC grades. Failure stress is defined as the first maximum in the tensile curve; ductile failure is characterized by a yield stress at typical strains of 6-7 \% followed by (stable) necking, whereas brittle failure is characterized by a breaking stress at $<6 \%$ strain. For MM-PC and HM-PC, the yield stress increases steadily with the number of steam-sterilization cycles. This phenomenon is well-known, and is related to the occurrence of physical aging [18]. Although the initial yield stress of these two grades is similar, the number of steam-sterilization cycles after which they become brittle differs considerably. The LM-PC grade also ages, but its yield stress increase cannot be observed because it already shows brittle failure after a single steam-sterilization cycle. This early brittle failure is related to the fact that its initial "apparent" molecular weight (see Table 1) is already below the critical level found by Gardner and Martin [4], i.e., $\bar{M}_{w}=33.800$ and $\bar{M}_{n}=14.300$. These results are now discussed in terms of the three mechanisms that contribute to the embrittlement: hydrolysis, aging, and microcavity formation.
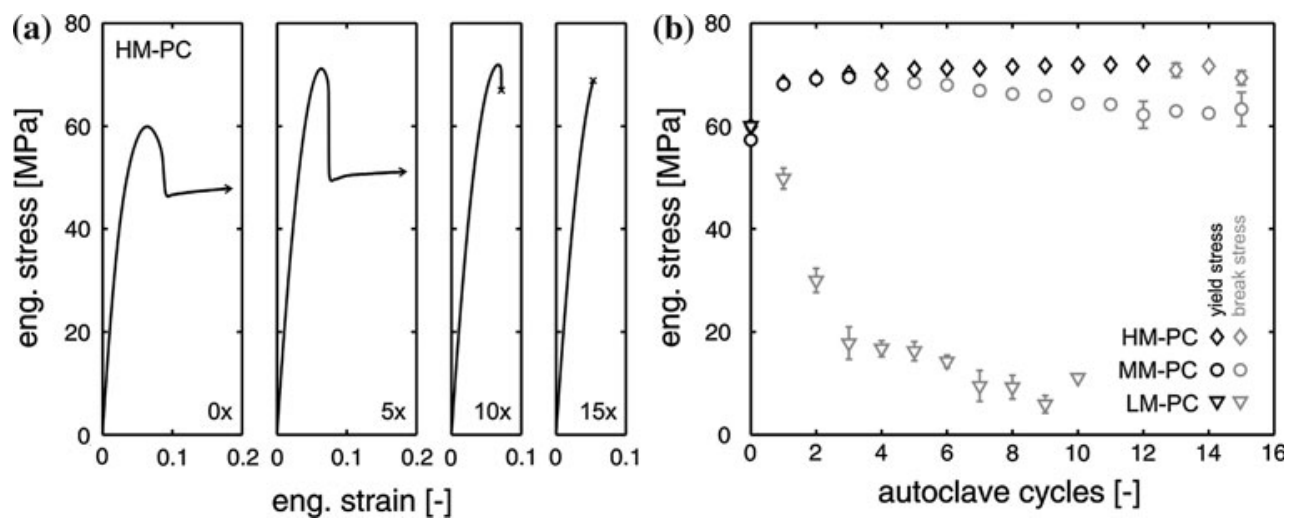

Fig. 1 Influence of steam-sterilization on the tensile behavior of polycarbonate. a Typical curves for HM-PC after 0, 5, 10, and 15 autoclave cycles. b Yield and break stresses of the three grades 


\section{Hydrolysis}

Long-term exposure to hot water or high temperature steam conditions can lead to dramatic reductions in molecular weight $[4,23,24]$. The relatively short exposure times used in this study are, however, insufficient to lead to a significant reduction, see Table 1. This is in agreement with observations made during continuous exposure of PC to steam at $125{ }^{\circ} \mathrm{C}$ and $1.4 \mathrm{~atm}$., where a significant reduction in molecular weight was found only after more than 50-100 h [23, 24].

\section{Physical aging}

The increase in yield stress resulting from repetitive steamsterilization cycles is now compared to the increase in yield stress upon dry annealing [2]. Time-temperature-superposition is employed to shift the measured yield stresses, annealed at different temperatures, to a single reference annealing temperature: $T_{\text {ref }}=23{ }^{\circ} \mathrm{C}$. The effective aging time, $t_{\text {eff }}$, is calculated according to Klompen et al. [20]:

$t_{\mathrm{eff}}(T(t))=\int_{0}^{t} a_{T}^{-1}\left(T\left(t^{\prime}\right)\right) d t^{\prime}$

Herein, $T$ is the temperature, $t$ the time, and $a_{T}$ is an Arrhenius type shift factor:

$a_{T}(T(t))=\exp \left(\frac{\Delta U_{a}}{R}\left(\frac{1}{T(t)}-\frac{1}{T_{\text {ref }}}\right)\right)$

where $\Delta U_{a}$ is the activation energy of aging $(205 \mathrm{~kJ} / \mathrm{mol}$ [20]) and $R$ the gas constant.

The open markers in Fig. 2 show the yield and break stresses of HM-PC and MM-PC as a function of effective aging time. The closed markers in Fig. 2 represent tensile yield stresses, measured by Engels et al. [2], of MM-PC after dry annealing at temperatures of 100,110 and $130{ }^{\circ} \mathrm{C}$. Clearly, the evolution of the yield stress induced by steam sterilization agrees well with that induced by dry annealing, indicating that the presence of steam does not significantly influence aging.

The increase in yield stress as a function of effective aging time can be described by [20]:

$\sigma_{y}(T(t))=\sigma_{y, 0}+c \cdot \log \left(\frac{t_{\mathrm{eff}}(T(t))+t_{a}}{t_{0}}\right)$

with $\sigma_{y, 0}=22.1 \mathrm{MPa}$ the reference stress level depending on loading rate (here for a strain rate of $1 \times 10^{-3} \mathrm{~s}^{-1}$ ), $c=3.60 \mathrm{MPa} /$ decade the slope of the increase in yield stress with respect to the logarithm of time, $t_{a}=3.5 \times 10^{10} \mathrm{~s}$ the initial age of the material, $t_{0}=1 \mathrm{~s}$.

The effective aging time that accumulates during each steam-sterilization cycle $t_{\text {eff,cycle }}$ can be calculated from the exact time-temperature history, or be approximated from the increase in yield stress after the first cycle, $\Delta \sigma_{y, 1 \text { st cycle }}$, in which case the effective time follows from:

$t_{\text {eff }, \text { cycle }}=t_{a} \cdot\left(10\left(\frac{\Delta \sigma_{y, 1 \text { st cycle }}}{c}\right)-1\right)$

Using Eq. 4, the increase in $t_{\text {eff }}$ per cycle is calculated to be $7.6 \times 10^{12} \mathrm{~s}$. The solid line in Fig. 2 illustrates that Eq. 3 accurately describes both the increase in yield stress resulting from dry annealing, as well as from steam sterilization.

Although the aging-induced evolution of the yield stress is the same for steam-sterilized and dry-annealed PC, Fig. 2 shows that the latter remains ductile up to much longer aging times. To understand this difference, it is important to realize that the fundamental cause for aging-induced embrittlement is not the increase in yield stress, but rather the accompanying increase in intrinsic strain softening. [16]. Near stress concentrations, intrinsic softening will lead to the initiation of localised plastic deformation zones. The higher the amount of softening, the more extreme this strain localization will be, and the higher the build-up of hydrostatic stress within the zone $[2,21]$. A brittle-to-ductile transition is subsequently triggered if the local hydrostatic stress exceeds a (molecular weight dependent) critical level, leading to incipient cavitation and craze initiation [2, 25].

In other words, aging makes the material more vulnerable to stress concentrations such as impurities, voids and microcavities.

\section{Microcavity formation}

For all three PC grades, disk-shaped microcavities are observed to form in the tensile bars after a number of

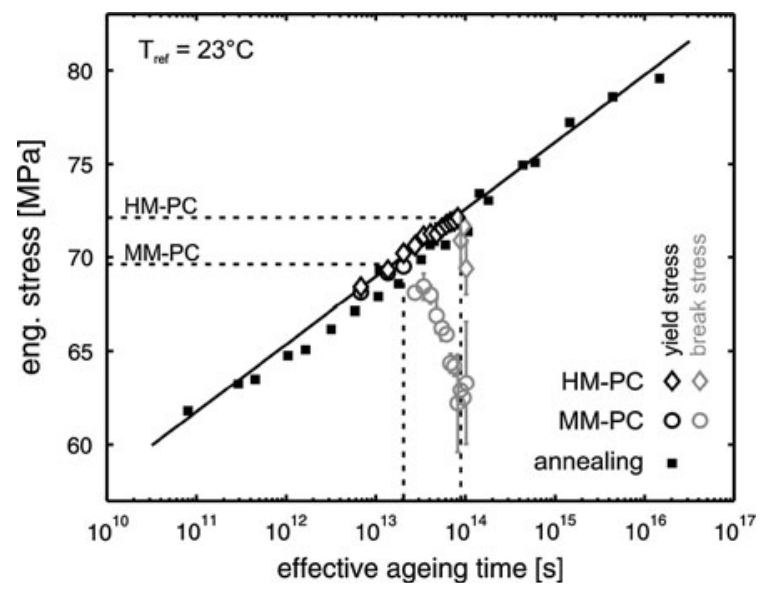

Fig. 2 A comparison of the yield stress evolution due to autoclave treatments and (dry) annealing. Open markers represent the same experimental data as in Fig. 1b, closed markers represent data taken from [2] and the solid line is a fit using Eq. 3 
Fig. 3 a Microcavities appear in the tensile bars due to the autoclave treatments. b These microcavities may lead to a localization of strain
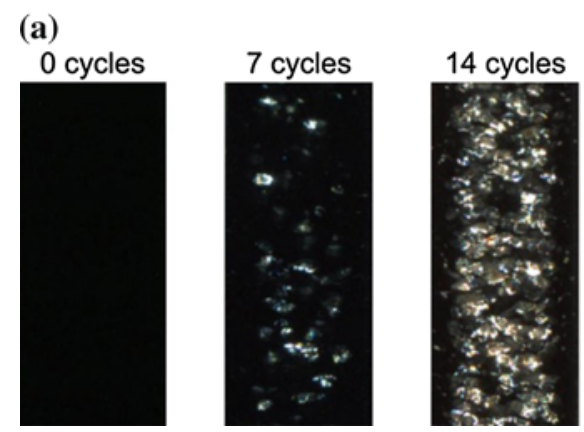

(b)

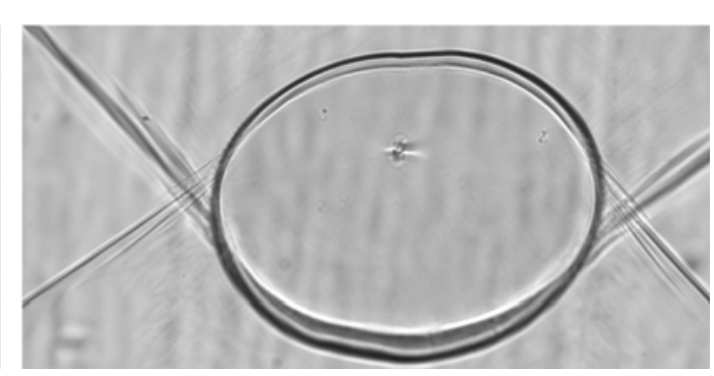

steam-sterilization cycles, which is consistent with observations reported in literature [3, 6, 7, 12-15]. Figure 3a shows tensile bars of MM-PC after 0, 7, and 14 steamsterilization cycles, clearly demonstrating the increasing presence of microcavities. When the material is stressed, these microcavities act as stress concentration sites and strain tends to localize around them, as shown in Fig. 3b. As these microcavities do not form upon dry annealing, this phenomenon explains why dry-annealed PC remains ductile much longer than steam-sterilized PC.

\section{Conclusion}

Three phenomena have been documented to contribute to the embrittlement of PC upon steam sterilization: hydrolysis, aging, and microcavity formation. At the time scale considered in this study, hydrolysis proves to have no influence since the decreases in molecular weight are insignificant. Aging, however, does play a major role because it decreases the material's ability to delocalize strain, making the material vulnerable to stress concentrations. The microcavities which form upon steam sterilization are just such stress concentrations. The embrittlement observed in steam-sterilized PC samples is therefore found to be a result of the interplay between aging and microcavity formation.

Open Access This article is distributed under the terms of the Creative Commons Attribution License which permits any use, distribution, and reproduction in any medium, provided the original author(s) and the source are credited.

\section{References}

1. Legrand DG (1969) J Appl Polym Sci 13:2129

2. Engels TAP, Van Breemen LCA, Govaert LE, Meijer HEH (2011) Polymer 52:1811

3. Robeson LM, Crisafulli ST (1983) J Appl Polym Sci 28:2925

4. Gardner RJ, Martin JR (1979) J Appl Polym Sci 24:1269

5. Ghorbel I, Thominette F, Spiteri P, Verdu J (1995) J Appl Polym Sci 55:163

6. Joseph EA, Paul DR, Barlow JW (1982) J Appl Polym Sci 27:4807

7. Golovoy A, Zinbo M (1989) Polym Eng Sci 29:1733

8. Flory PJ (1945) J Am Chem Soc 67:2048

9. Gent AN, Thomas AG (1972) J Polym Sci A2 Polym Phys 10:571

10. Bersted BH, Anderson TG (1990) J Appl Polym Sci 39:499

11. Vincent PI (1960) Polymer 1:425

12. Li C, Zhang Y, Zhang Y (2003) J Appl Polym Sci 89:589

13. Narkis M, Bell JP (1982) J Appl Polym Sci 27:2809

14. Narkis M, Nicolais L, Apicella A, Bell JP (1984) Polym Eng Sci 24:211-217

15. Qayyum MM, White JR (1991) J Appl Polym Sci 43:129

16. Van Melick HGH, Govaert LE, Meijer HEH (2003) Polymer 44:3579

17. Golden JH, Hammant BL, Hazell EA (1967) J Appl Polym Sci 11:1571

18. Bauwens-Crowet C, Bauwens J-C (1982) Polymer 23:1599

19. Hutchinson JM, Smith S, Horne B, Gourlay GM (1999) Macromolecules 32:5046

20. Klompen ETJ, Engels TAP, Govaert LE, Meijer HEH (2005) Macromolecules 38:6997

21. Van Melick HGH, Bressers OFJT, Den Toonder JMJ, Govaert LE, Meijer HEH (2003) Polymer 44:2481

22. Kramer EJ (1983) In: Kausch HH (ed) Crazing in polymers. Advances in polymer science, vol 91/92, Berlin, Springer, pp 1-56

23. Pryde CA, Hellman MY (1980) J Appl Polym Sci 25:2573

24. Schilling FC, Ringo WM Jr, Sloane NJA, Bovey FA (1981) Macromolecules 14:532

25. Van Melick HGH, Govaert LE, Meijer HEH (2003) Polymer 44:457 